\title{
Application of Intelligent Technology of Electrical Apparatus in Distribution Network Automation
}

\author{
Jie Yang, Tao Xia, Yu Ye, Weiping Li, Jianmin Huang, Yong Tan, Ken Chen, \\ Changdong Zhu, Xibing Guan, Jing Hua
}

Yichang Power Supply Company, State Grid Corporation of Hubei Province, Yichang 443000, Hubei, China

Keywords: electrical intelligent technology, electrical function, distribution network automation, application.

\begin{abstract}
In the context of the rapid development of China's national economy and the continuous progress of science and technology, the electrical industry has also made rapid development, towards the intelligent direction, which also effectively promoted China's national economic development, and for people's Life and work to bring great convenience. At the same time, people on the electrical function also put forward higher and higher requirements. Electrical intelligent technology not only affects the quality of electrical appliances, but also affect the operation of the power system. Therefore, it should be in the system of scientific use of electrical automation technology, and thus effectively promote the development of intelligent electrical appliances, to better meet people's electrical needs, enhance people's quality of life. This paper mainly analyzes the application of intelligent technology in the distribution network automation, hoping to play a certain role in promoting the development of electrical appliances, and thus effectively improve people's quality of life.
\end{abstract}

\section{Background}

The construction of intelligent distribution network can make up the drawbacks of the traditional distribution network to a large extent. In the process of intelligent distribution network construction, it is necessary to apply the power distribution automation technology. This technology has a very important influence on the safe operation of the distribution network, Based on the power sector needs of the power distribution automation technology for continuous research, so as to intelligent power distribution network construction to provide a strong technical support [1].

Application Status of Distribution Automation Technology in Intelligent Distribution Network Construction.

First, the overall structure of the intelligent distribution network is not rigorous. The overall structural design of the intelligent distribution network has a very important impact on the quality of its construction. However, most power companies are not aware of the importance of the overall structural design of the intelligent distribution network. In the design process, the actual situation and all the influencing factors can not be carried out. Comprehensive analysis, the overall structure of the design is not rigorous problems in the late put into use in the practical performance greatly reduced, and there is a big security risk, leading to the distribution network can not be very good for people to provide adequate and stable energy, industry development Subject to certain restrictions.

Second, China's intelligent distribution network distribution imbalance. After the investigation of the relevant personnel found that China's intelligent distribution network distribution imbalance [2], mainly including the distribution of more dispersed and alienated in the central and western regions is particularly evident, due to distribution network distribution imbalance caused by the phenomenon of optical fiber instability, which Kind of phenomenon will lead to the distribution network in the course of the operation will be different levels of fault problems, to people's production and life has brought great inconvenience [3].

Third, the power distribution automation technology lack of perfection. China's use of power distribution automation time is short, although the researchers on the technology for continuous 
research, but compared with the Western developed countries still have a big gap. In the power distribution automation device on the less research, usually need to introduce foreign automation devices [4], and power companies on how to use the device and control technology and other aspects of understanding is not comprehensive, resulting in the distribution of automation technology in the practical application process Many deficiencies, the normal operation of the distribution network to adversely affect [5].

\section{Electrical Intelligent Technology}

\subsection{PLC Automation Intelligent Control}

In the control of electrical engineering automation systems, the process flow and the control of the switch with the development of the power industry and continuous development. This also makes the intelligent PLC system is gradually applied by the electrical business, through the system staff may be in the control room on the relay and other direct real-time control, so that the production efficiency has been improved. At the same time with the continuous development of intelligent technology and progress, power supply system has gradually realized the intelligent control, and completed the automatic switching, and further improve the electrical system reliability and security [6].

\subsection{Adaptive Control}

In the intelligent control, the adaptive control is a very important link, the electrical engineering automation control system in the actual operation always need to face the changing situation, also requires the control parameter also needs the corresponding change The And the solution of this problem also requires intelligent technology, as the neural network adaptive control system, the control strategy is not fixed, but because the system has a certain learning function, it can be based on the surrounding environment test results, Adaptive change of control strategy. The use of intelligent technology, so that the electrical engineering to achieve unattended and unmanned surveillance and combined with the actual operation of the substation to carry out the corresponding intelligent changes, through the computer equipment to achieve the computer network information, through the computer cable to meet the data transmission Automation, so that its work efficiency and accuracy to be effectively improved.

\subsection{Automated Machine Fault Detection Processing}

In the course of the operation of electrical engineering, the corresponding automation equipment and equipment to use a long time, if you ignore the maintenance of machinery and equipment, then once the equipment fails, it will take a lot of time to check and deal with, but the application of intelligent technology After that, these problems can be effectively resolved, through the computer technology, the status of each device in real-time monitoring, in the event of failure to timely record the fault and determine the trend of failure, not only saves the time of fault detection, but also to ensure failure The diagnosis is safer and more reliable. After all, for the electrical engineering automation control process failures are not caused by human factors, and with uncertainty, once not timely or correct handling, will have a safe and stable operation of the power system adversely affected [7].

\section{Intelligent Electrical Functional Requirements}

As an important part of intelligent electrical appliances, intelligent unit is mainly set in the traditional electrical switch position. It has a variety of functions, including communication, measurement and control, so that it can make the electrical function more complete, more powerful.

(1) Measurement function. Intelligent electrical appliances with energy metering and power measurement function, but also in the electronic screen to quickly display the measurement results, and can fully guarantee the accuracy and reliability of measurement results [8].

(2) Communication function. This capability provides information transmission services for substation automation systems and appliances, enabling them to obtain more accurate and real-time information to meet their operational requirements and ensure their proper operation [9]. 
(3) Online monitoring function. The use of sensors to complete the online monitoring work, the main monitoring content, including the performance of electronic insulation and temperature.

(4) Protection function. Can rely on the protection of the computer to complete the work of the previous relay protection, more convenient and intelligent.

(5) Control function. Intelligent electrical appliances with the control system can be integrated to consider the cost, security, etc., to achieve effective control of the circuit breaker, so that it can complete the sub-closing operation.

\section{The Application of Intelligent Electrical Technology in the Automation System of Distribution Network}

Intelligent electrical appliances mainly include man-machine dialogue, single-chip system, the amount of input and analog input, etc., of which some modules will use plug-ins to connect.

\subsection{Intelligent Electrical Technology is Mainly Built on the Distribution Network System Automation}

Intelligent electrical communication function, mainly used in substation electrical monitoring system or automation system, and can be used in the distribution network automation system RTU equipment, the main role is the two-way transmission of information. The intelligent electrical appliance can transmit the controlled object, the operating parameter, the fault information and the protection setting value to the RTU device or the system machine. The system machine transmits a series of operation instructions to the intelligent electrical appliance, Adjust and change. In addition, the communication function can be achieved through the serial communication interface, if the power of the system application of the field bus, smart appliances will use field bus technology.

\subsection{Smart Appliances Can Provide Hardware Implementation Conditions}

Electrical appliances all the functions need to be sufficient in the power supply conditions can be achieved under the conditions, if the lack of adequate supply of electricity, it will lead to electrical appliances can not be put into use, thus hindering the electronic and intelligent development. At present, the automation of the distribution network can automatically divide the distribution area to ensure the timeliness and reliability of the power supply. Intelligent electrical in accordance with the principle of distribution and partition management monitoring electrical appliances, once found abnormal electrical operation, you can take appropriate measures to ensure that the power supply is normal.

\subsection{Intelligent Appliances Can Improve Reliability}

Intelligent electrical stabilization power supply can suppress external noise, such as: impulse noise, arc discharge and lightning, etc., which is mainly through the discrete components and DC regulator, conventional AC voltage regulator and isolation pressure to match, and through the system on the switch Power supply to choose, or add a standard power supply filter to ensure that the distribution network automation monitoring system in essence and the practical application of consistency. This will not only reduce the external interference, strengthen the equipment itself, anti-interference ability, and can improve the automation system configuration and reliability.

\subsection{Smart Appliances Can Improve Economic Efficiency}

The automation of the distribution network can be arranged according to the actual needs of each region, which can reduce the unnecessary waste and line layout, and can choose the optimal layout of the line. In addition, the line operation and maintenance and management process, are generally related maintenance personnel around the inspection, carefully check the line running. This maintenance process often takes a lot of money, manpower and material resources. But the implementation of the distribution network automation, you can automatically check the line through the system operation, and this automated inspection accuracy and speed are better than man-made operation, can greatly improve the efficiency of work, reduce maintenance costs, thereby improving economic efficiency.

\section{Intelligent Electrical Appliances in China's Application Advantages}


Improve the distribution automation technology in the construction of intelligent distribution network in the application of the level of Western developed countries in the intelligent distribution network construction has made some achievements in China's intelligent distribution network construction process can learn from foreign experience, and let the professional Personnel on the distribution of automation technology for more in-depth study, so as to improve the quality of intelligent distribution network construction to ensure the normal operation of the distribution network. The author puts forward the following measures to improve the application level of distribution automation technology in intelligent distribution network construction.

First, build a scientific and rational management system. In order to make the application of distribution automation technology to achieve better results, the power sector needs to build a scientific and rational management system according to the actual situation, the distribution network information technology and operation of the unified management, so that the management between the information , Technical communication and exchange, the timely operation of the power grid to solve the problem, so that the intelligent distribution network for better control, so that it can be safe and stable operation.

Second, optimize the distribution of information automation between the various departments of the power system. Electric power enterprises and the various departments to achieve the goal of information sharing between the power management system to improve the unified management and distribution automation technology has a certain positive role in stability, and intelligent distribution network can be the actual operation of real-time monitoring and Control, so as to better ensure its safe and stable operation, to provide people with adequate power. At the same time, the unified management of power information technology system speeds up the operation of data and information transmission, and in the transmission process of information and data loss is significantly reduced, the control staff can be the first time to obtain intelligent distribution network to run the data and Information, can be found in the process of running the existing problems, take timely and effective measures to solve, and can prevent some of the fault problems, so that the normal operation of the distribution network is guaranteed.

Third, increase the scope of application of Internet technology. China's science and technology was the rapid development trend, some new technologies came into being, Internet technology in all walks of life has been widely used, and achieved good results in the intelligent distribution network construction process using Internet technology Power grid system tends to improve, for this power enterprises in the distribution network construction process needs to continue to increase the scope of application of Internet technology. The use of Internet technology to reduce the cost of construction of intelligent distribution network for the power companies to bring more economic benefits, so that the safety of intelligent distribution network to greatly improve the operation, while the power distribution automation technology in the power The effect of information technology is given full play. In addition to the use of Internet technology can allow different departments of power companies and different regions of the management of the distribution network and distribution lines on the network to conduct a careful understanding of the intelligent distribution network to improve the degree of information.

\section{Conclusion}

In short, the application of power automation system technology in the operation and management of distribution network, improve the automation level of distribution network operation, strengthen the construction of distribution network automation is of great significance, not only can reduce the probability of power grid failure, to ensure the stability of power supply And continuity, but also can reduce the cost of grid operation, improve the economic efficiency of power companies. Therefore, the power companies should pay attention to the automation of distribution network construction, and actively take effective measures to improve the automation of distribution network operation and management to promote China's power industry faster and better development.

\section{References}


[1] Chen Huan, et al. Analysis of power automation system technology in the distribution network operation and management of the application of Science and Technology, 2015Vol. (02), p.79.

[2] $\mathrm{Hu}$ Xiaodong, et al. Talking about the Application of Electric Power Automation System Technology in Distribution Network Operation and Management. Henan Science and Technology, 2013Vol. (16), p.75.

[3] Li Jun, et al. Talking about the application of power automation system technology in distribution network operation and management. Henan Science and Technology, 2013 Vol. (15), p.77.

[4] Zhu Cheng, et al. Explore the application of intelligent technology in the automation of mechanical engineering. Science and Technology Economic Guide, 2017, Vol. 1 (15), p.91-92.

[5] Shan Yunfeng, et al. Intelligent technology in the application of mechanical engineering automation. Shandong Industrial Technology, 2017, Vol. 2 (1), p.87-89.

[6] Ma Lei, et al. Intelligent technology in the application of mechanical engineering automation. Shandong Industrial Technology, 2015, Vol. 6 (15), p.105-107.

[7] Yao Bohua, et al. Distribution network automation technology in the distribution network operation and maintenance of the application of industrial c, 2016, Vol. 8 (20), p.274-275.

[8] Wang Shunhua, et al. Urban distribution network line automation intelligent technology application. China Science and Technology aspect, 2014, Vol. 4 (23), p.200-201.

[9] He Chuan, et al. Urban distribution network automation intelligent technology application. China's new technology and new products, 2015, Vol. 1 (23), p.28- 29. 